\title{
ABORDAGENS TEÓRICO-METODOLÓGICAS DE PESQUISA EM POLÍTICA EDUCACIONAL: DO PLANEJAMENTO AO METATEXTO
}

\author{
Ricardo Inocêncio Pereira ${ }^{1}$ \\ Marcia Regina Selpa Heinzle ${ }^{2}$
}

\section{Resumo}

Este artigo traz reflexões acerca de uma pesquisa já concluída sobre recontextualizações do Programa Ensino Médio Inovador (ProEMI), enquanto política de redesenho curricular. O objetivo do texto é explicar como as opções teóricas e metodológicas levaram ao desenho da pesquisa e como suas imbricações contribuíram desde a fase de planejamento até a comunicação dos resultados. O desenho da pesquisa foi elaborado com base no conceito de recontextualização, no Ciclo de Políticas e na Teoria da Atuação das Políticas. O metatexto foi produzido a partir da Análise Textual Discursiva (ATD) do corpus, da qual emergiram ações e experiências inovadoras, bem como tensões na atuação da política. O quadro teóricometodológico contribuiu significativamente para uma análise ampla da política, considerando as recontextualizações que ocorrem do macro ao microcontexto.

Palavras-chaves: Ciclo de Políticas; Análise textual discursive; ProEMI; Recontextualizações; Atuação da Política

\section{THEORETICAL-METHODOLOGICAL APPROACHES OF RESEARCH IN EDUCATIONAL POLICY: FROM PLANNING TO METATEXT}

\begin{abstract}
\footnotetext{
${ }^{1}$ Ricardo Inocêncio Pereira, Mestrando em Educação (Bolsista UNIEDU/FUMDES), Universidade Regional de Blumenau. E-mail: pricardopereira@hotmail.com

2 Marcia Regina Selpa Heinzle, Doutora em Educação, Universidade Regional de Blumenau. E-mail: selpamarcia@gmail.com
} 
This article reflects on an already completed research on recontextualizations of Ensino Médio Inovador Program (Innovative High School Program - ProEMI), as a curriculum redesign policy. The objective of the text is to explain how the theoretical and methodological options led to the research design and how its interconnections contributed from the planning phase to the communication of the results. The research design was elaborated based on the recontextualization concept, in the Policy Cycle and in the Policy Enactment Theory. The metatext was produced from the Discursive Textual Analysis of the corpus, from which emerged innovative actions and experiences, as well as tensions in the policy enactment. The theoretical-methodological framework contributed significantly to a broad policy analysis, considering the recontextualizations that occur from the macro to the microcontext.

Keywords: Policy Cycle; Discursive Textual Analysis; ProEMI; Recontextualizations; Policy Enactment

\title{
ENFOQUES TEÓRICO-METODOLÓGICOS DE INVESTIGACIÓN EN POLÍTICA EDUCACIONAL: DE LA PLANIFICACIÓN AL METATEXTO
}

\begin{abstract}
Resumen
Este artículo trae reflexiones sobre una investigación ya concluida sobre recontextualizaciones del Programa Enseñanza Media Innovadora (ProEMI), como política de rediseño curricular. El objetivo del texto es explicar cómo las opciones teóricas y metodológicas llevaron al diseño de la investigación y cómo sus interconexiones contribuyeron desde la fase de planificación hasta la comunicación de los resultados. El diseño de la investigación fue elaborado con base en el concepto de recontextualización, en el Ciclo de Políticas y en la Teoría de la Actuación de las Políticas. El metatexto fue producido a partir del Análisis Textual Discursivo del corpus, del que surgieron acciones y experiencias innovadoras, así como tensiones en la actuación de la política. El marco teórico-metodológico contribuyó significativamente a un análisis amplio de la política, considerando las recontextualizaciones que ocurren del macro al microcontexto.
\end{abstract}

Palabras clave: Ciclo de Políticas; Análisis Textual Discursivo; ProEMI; Recontextualización; Actuación de la Política 


\section{INTRODUÇÃO}

Neste artigo trazemos algumas reflexões acerca do percurso metodológico de uma pesquisa já concluída (PEREIRA, 2017) sobre recontextualizações do Programa Ensino Médio Inovador (ProEMI), enquanto política de redesenho curricular. O propósito do texto consiste em explicar como as opções teóricas e metodológicas levaram ao desenho da pesquisa e como suas imbricações contribuíram desde a fase de planejamento até a comunicação dos resultados.

Inicialmente, durante a fase de delimitação do tema, Lopes (2005) nos auxiliou a compreender que, no contexto de globalização no qual vivemos atualmente, há um intercâmbio crescente de textos e discursos, levando a políticas curriculares de países distintos parecerem similares. Compreendemos essa dinâmica como parte de uma realidade que Ball (2014) define como cada vez mais cosmopolita.

Voltamos nosso olhar para Programa Ensino Médio Inovador (ProEMI), entendido enquanto política educacional e, como tal, formulado para um contexto específico, em um determinado tempo histórico. Assim sendo, apresenta orientações oficiais elaboradas em meio a debates, disputas e influências, e passa por resistências e reinterpretações em cada contexto político específico. Como está sujeito a recontextualizações, o Programa repercute diferentemente em cada região, resultando em variadas práticas nas escolas e no trabalho dos profissionais que atuam nelas. Nesse sentido,

\footnotetext{
estudiosos do campo do currículo vêm sinalizando para a relevância de ampliar o debate sobre as políticas curriculares nos contextos das práticas institucionais. Destacam a necessidade de explorar investigações das políticas de currículo de modo a compreender, com maior clareza, as formulações das propostas e os embates políticos no nível global e local. (ANDRADE, 2012, p.37)
}

Considerando essas preocupações com as políticas curriculares, assim como o nosso interesse em torno do Ensino Médio (EM), começamos a nos questionar sobre as recontextualizações pelas quais passa a política de redesenho curricular do ProEMI do nível nacional (macrocontexto) até o nível local (microcontexto). Com base no Estado da Questão, sentimos necessidade de desenvolver uma pesquisa que abrangesse as recontextualizações que ocorrem desde as influências presentes na produção do discurso oficial (nacional e estadual) até a prática no cotidiano da escola. 
Na próxima seção, exploramos o conceito de recontextualização, que perpassa toda a nossa proposta de investigação, dialogando especialmente com Lopes (2005), Mainardes e Stremel (2010), a partir de Bernstein (1996; 1998). Em seguida, com base, principalmente, na compreensão de Mainardes (2006), trazemos o Ciclo de Políticas, proposto por Stephen Ball e seus colaboradores (BOWE et al, 1992; BALL, 1994), além da Teoria da Atuação das Políticas (policy enactment) apresentada por Ball, Maguire e Braun (2016).

Em seguida, apresentamos processo de ATD (MORAES, 2003; MORAES; GALIAZZI, 2006) e o desenho da pesquisa. Finalizamos o texto trazendo as contribuições do quadro teórico-metodológico para chegarmos aos resultados e comunicá-los em um metatexto.

\section{RECONTEXTUALIZAÇÕES: O CICLO DE POLÍTICAS E A TEORIA DA ATUAÇÃO}

Nos remetemos, primeiramente, à teoria do dispositivo pedagógico de Bernstein, partindo das discussões de Lopes (2005), Mainardes e Stremel (2010). Esse dispositivo, segundo Bernstein (1996, p. 254), fornece a "gramática intrínseca do discurso pedagógico" através de regras hierarquicamente relacionadas: as distributivas, as recontextualizadoras e as avaliativas.

Nos interessam mais diretamente, nesta pesquisa, as regras recontextualizadoras do discurso. É por meio da recontextualização que o discurso pedagógico "se desloca do seu contexto original de produção para outro contexto onde é modificado (através de seleção, simplificação, condensação e reelaboração) e relacionado com outros discursos e depois é relocado" (MAINARDES; STREMEL, 2010, p.43). São, portanto, as regras de recontextualização que fixam "os limites externos e internos do discurso legítimo" (LOPES, 2005, p.54).

Bernstein diferencia dois campos recontextualizadores, nos quais atuam as regras de recontextualização (LOPES, 2005; MAINARDES; STREMEL, 2010):

a) O Campo Recontextualizador Oficial (CRO) produz o discurso pedagógico oficial (DPO), que regula os discursos pedagógicos legítimos, incluindo os conhecimentos e as práticas pedagógicas a serem transmitidas pelas escolas. É criado e dominado pelo Estado e suas agências, autoridades ou departamentos.

b) O Campo de Recontextualização Pedagógica (CRP) tem a função de criar a autonomia fundamental da educação, preocupando-se também, assim como o CRO, com os 
princípios e práticas reguladores dos movimentos dos discursos da produção a sua reprodução. É constituído principalmente por educadores, pesquisadores da educação e produtores de literatura especializada.

Lopes (2005, p.55) argumenta que o conceito de recontextualização, formulado por Basil Bernstein, tem um enfoque marcadamente estruturalista ${ }^{3}$, visto que

o autor situa a definição muito estratificada e compartimentada dos diferentes campos que atuam na recontextualização, especialmente aqueles formados pelo Estado e pelas organizações de produção do conhecimento pedagógico. As tensões, os conflitos e os acordos, tanto nos campos recontextualizadores pedagógico oficial e não-oficial implicam que as relações entre esses campos precisem ser consideradas como constantes no processo de constituição das políticas. (LOPES, 2005, p. 55).

A autora analisa que há múltiplas associações entre agentes e práticas, que inclusive elaboram discursos contrários "às orientações dominantes no contexto oficial, não sendo possível afirmar a homogeneidade dos discursos nesses dois campos, nem tampouco a possibilidade de não-articulação entre ambos" (LOPES, 2005, p.55). No entanto, Lopes defende a importância do conceito de recontextualização para a pesquisa das políticas de currículo, principalmente pela relação entre poder e saber a qual remete o modelo teórico, e pela possibilidade de

marcar as reinterpretações como inerentes aos processos de circulação de textos, articular a ação de múltiplos contextos nessa reinterpretação, identificando as relações entre processos de reprodução, reinterpretação, resistência e mudança, nos mais diferentes níveis. (LOPES, 2005, p. 55).

Para Lopes (2005) a busca pela articulação macro-micro destaca-se como aspecto mais produtivo do conceito de recontextualização desenvolvido por Bernstein para o entendimento das políticas de currículo, isto porque, sua teoria visa à identificação das regras do processo educacional nas escolas, para posteriormente relacioná-las às condições estruturais, situando a análise num contexto mais amplo.

Esse conceito, também vem sendo associado por Ball ao de hibridismo ${ }^{4}$, ao se apropriar das discussões culturais pós-estruturalistas e pós-coloniais. Desse modo, defende que no

\footnotetext{
${ }^{3}$ Lopes (2005, p. 61) utiliza o termo estruturalismo para designar "o conjunto de perspectivas de investigação e de modos de pensamento que têm por base a compreensão das estruturas sociais em um sentido mais geral e amplo".

4 "É a partir da ideia de uma mistura de lógicas globais, locais e distantes, sempre recontextualizadas, que o hibridismo se configura" (LOPES, 2005, p.56).
} 
mundo globalizado, os processos de recontextualização são produtores de discursos híbridos e que há um ciclo contínuo de produção de políticas sujeito a esses processos (LOPES, 2005).

Tendo esse entendimento teórico, e levando em conta o debate atual em torno da identidade e do currículo do Ensino Médio, chegamos à delimitação do objeto de pesquisa e à definição do objetivo geral, que consiste em compreender como a política de redesenho curricular do Programa Ensino Médio Inovador - ProEMI é recontextualizada do macro ao microcontexto, isto é, desde o Governo Federal, passando pela Secretaria de Estado da Educação e a Gerência Regional de Educação - GERED, até chegar à prática dos profissionais de uma escola da Rede Estadual de Santa Catarina.

Analisar um Programa como o ProEMI, assim como qualquer outra política educacional, consiste numa tarefa desafiadora. Existe um grande risco de se tratar do objeto de estudo de uma maneira superficial ou com uma visão unidirecional, baseada no ponto de vista do pesquisador e de suas ideias pré-concebidas. Por isso, procuramos por um referencial teórico-analítico consistente, que não enfatizasse unicamente o controle do Estado.

Levando em consideração a natureza complexa e controversa das políticas educacionais, optamos pela abordagem do Ciclo de Políticas que, segundo Mainardes (2006), indica a necessidade de articular os processos macro e micro, considerando a ação dos profissionais no nível local. Para ele,

[...] o foco da análise de políticas deveria incidir sobre a formação do discurso da política e sobre a interpretação ativa que os profissionais que atuam no contexto da prática fazem para relacionar os textos da política à prática. Isso envolve identificar processos de resistência, acomodações, subterfúgios e conformismo dentro e entre as arenas da prática, e o delineamento de conflitos e disparidades entre os discursos nessas arenas. (MAINARDES, 2006, p. 50).

Com esse entendimento, ao propormos analisar uma política educacional com foco na formação do discurso da política considerando as influências, as disputas e resistências presentes na produção dos textos das políticas, bem como na ação dos profissionais no microcontexto (professores e equipe gestora), seguimos a tendência atual da Sociologia da Educação, o retorno ao ator social. Propusemo-nos a ouvir, interpretar e compreender as vozes dos interlocutores envolvidos nas interpretações das políticas educacionais, na sua produção e na prática cotidiana da escola, na tentativa de superar a visão de que as políticas são produzidas pelo Estado e posteriormente implementadas.

Ainda, de acordo com Mainardes (2006), essa abordagem, formulada pelo sociólogo inglês Stephen Ball e colaboradores (BOWE et al, 1992; BALL, 1994), é relevante e vem 
sendo muito utilizada em diferentes países, como no Brasil, onde o campo de pesquisa em políticas educacionais é relativamente novo. Além disso, "permite uma análise crítica e contextualizada de programas e políticas educacionais desde sua formulação até a sua implementação no contexto da prática, bem como seus resultados/efeitos" (MAINARDES, 2006, p. 48).

No entanto, este referencial teórico-analítico não foi adotado como um caminho rígido para a pesquisa, a ponto de formatá-la dentro de limites estabelecidos pois, como defende Mainardes (2006, p. 49), o Ciclo de Políticas "não é estático, mas dinâmico e flexível”. Por isso, a ideia de um ciclo contínuo, constituído por três contextos principais, interrelacionados, que não têm uma dimensão temporal ou sequencial, nem constituem etapas lineares: o contexto de influência, o contexto da produção de texto e o contexto da prática. Há ainda outros dois contextos, acrescentados mais tarde: o contexto dos resultados ou efeitos e o contexto da estratégia política.

Segundo Mainardes (2006), o contexto de influência é onde os discursos políticos são construídos, havendo disputas de interesse de diferentes grupos com o intuito de influenciar a definição das finalidades sociais da educação e do que é ser educado. É também no contexto de influência que, conforme os conceitos adquirem legitimidade, se forma um discurso de base para a política.

Além das redes sociais dentre e em torno dos partidos políticos, do governo e do processo legislativo, é importante considerar as influências globais e internacionais no processo de formulação das políticas nacionais. Essas influências externas, em tempos de globalização e internacionalização, são de natureza bem diversa, sendo disseminadas basicamente de duas maneiras: pelo fluxo de ideias por meio de redes políticas e sociais, e pelo patrocínio de agências multilaterais, que impõem supostas soluções baseadas nos interesses do mercado. No entanto, essas ideias são sempre recontextualizadas, havendo uma interação dialética entre global e local.

Outro contexto, o da produção de texto, é considerado por Mainardes (2006) como o mais simples e evidente. Os textos que representam a política podem tomar várias formas: textos legais oficiais e textos políticos, comentários formais ou informais sobre os textos oficiais, pronunciamentos oficiais, vídeos etc. Tais textos são resultados das disputas e acordos de grupos que competem para controlar as representações da política, não sendo necessariamente coerentes e claros, carregando limitações materiais e possibilidades. 
Há ainda o contexto da prática, onde acontecem as vivências dos textos políticos, emergindo seus efeitos e suas consequências. Esse contexto está sujeito à interpretação e recriação, podendo representar mudanças e transformações significativas na política original. Não acontece, portanto, uma simples implementação, pois o que os professores e demais profissionais pensam e idealizam levam a interpretações diversas, que fazem com que essas políticas sejam recriadas na prática. Além disso, as diferentes interpretações também disputam entre si, prevalecendo algumas vozes sobre outras, dependendo de interesses diversos (MAINARDES, 2006).

O contexto dos resultados ou efeitos, de acordo com Mainardes (2006), preocupa-se com questões de justiça, igualdade e liberdade individual. Nesse contexto, as políticas deveriam ser analisadas em termos do seu impacto e das interações com desigualdades existentes, utilizando as políticas locais ou as amostras de pesquisas como ponto de partida para a análise de questões mais amplas da política.

O último contexto, o de estratégia política, envolve a identificação de um conjunto de atividades sociais e políticas que seriam necessárias para lidar com as desigualdades criadas e reproduzidas pela política investigada. Nesse contexto, o pesquisador pode contribuir de forma mais direta para fomentar o debate em torno da política em questão (MAINARDES, 2006).

Entretanto, delineamos nossa pesquisa em torno dos três primeiros contextos: de influência, de produção de texto e da prática. Essa opção foi mais adequada aos objetivos da pesquisa ao se sustentar na posição mais recente do próprio Ball que "tem indicado que o contexto dos resultados/efeitos é uma extensão do contexto da prática, e o contexto da estratégia/ação política pertence ao contexto de influência" (MAINARDES; FERREIRA; TELLO, 2011, p. 158).

Complementando algumas ideias presentes no Ciclo de Políticas, teve importante contribuição para o desenvolvimento da pesquisa a Teoria de Atuação das Políticas (policy enactment $)^{5}$, formulada por Ball, Maguire e Braun (2016). A intenção é contrapor-se à ideia de implementação, superando o binário política e prática, ao mostrar que as escolas e os professores fazem política na prática. Partindo de um trabalho empírico realizado em quatro escolas secundárias na Inglaterra, os autores defendem que as escolas são locais únicos de

\footnotetext{
${ }^{5}$ Em face das dificuldades de tradução do termo policy enactment (ver ALFERES, 2017, p. 92), optamos pela utilização do termo "atuação das políticas", conforme o livro Como as escolas fazem as políticas: atuação em escolas secundárias (ver BALL; MAGUIRE; BRAUN, 2016, p. 12).
} 
atuação das políticas e que, na prática, as mesmas políticas podem ser interpretadas e traduzidas de diferentes maneiras.

Ao tratar do Ciclo de Políticas em uma entrevista (MAINARDES; MARCONDES, 2009), Stephen J. Ball já declarava sua rejeição à ideia de que as políticas são implementadas, pois isso sugeriria uma linearidade no seu movimento em direção à prática, como se isso acontecesse de forma direta.

Assim, a pessoa que põe em prática as políticas tem que converter/transformar essas duas modalidades, entre a modalidade da palavra escrita e a da ação, e isto é algo difícil e desafiador de se fazer. E o que isto envolve é um processo de atuação, a efetivação da política na prática e através da prática. É quase como uma peça teatral. Temos as palavras do texto da peça, mas a realidade da peça apenas toma vida quando alguém as representa. E este é um processo de interpretação e criatividade e as políticas são assim. (MAINARDES; MARCONDES, 2009, p. 305).

Considerando os contextos do Ciclo de Políticas e concebendo os profissionais da escola como os principais atores das políticas no contexto da prática, retomamos a discussão anterior sobre a recontextualização. Segundo Lopes (2005, p. 56), Ball considera

as articulações e reinterpretações em múltiplos contextos, que vão das influências internacionais às práticas escolares, sem estabelecer hierarquias entre os mesmos. Os contextos de influência internacional, o contexto de definição de textos e os contextos da prática formam um ciclo contínuo produtor de políticas sempre sujeitos aos processos de recontextualização.

Levamos em consideração, também, que para o desenvolvimento de pesquisas em políticas educacionais de modo aprofundado e evitando qualquer forma de legitimação, é necessária uma perspectiva de totalidade, isto é, o estabelecimento dos "devidos vínculos com o contexto mais econômico, político e social", e a análise "das relações das políticas com a justiça social.” (BALL; MAINARDES, 2011, p. 13). Por isso, ao longo do desenvolvimento da pesquisa, foi importante estabelecermos um diálogo constante com o Ciclo de Políticas, a Teoria da Atuação e o conceito de recontextualização.

\section{A ANÁLISE TEXTUAL DISCURSIVA}

Por sua abordagem qualitativa, esta análise exige grande empenho no trabalho com os dados, com a intenção de ir além da mera descrição, procurando interpretar e argumentar. Nesse processo, a análise textual discursiva (MORAES, 2003; MORAES; GALIAZZI, 2006) 
proporcionou importante auxílio e possibilitou um diálogo com a base teórica e com as categorias emergentes de cada objetivo da pesquisa, contribuindo para que considerássemos a inter-relação entre os contextos do Ciclo de Políticas.

Moraes (2003, p. 209) define a ATD com "um processo auto-organizado de produção de novas compreensões em relação aos fenômenos que examina", alcançado por meio de uma análise rigorosa e criteriosa, o que é relevante para pesquisas qualitativas.

\begin{abstract}
No seu conjunto, as etapas desse ciclo podem ser caracterizadas como um processo capaz de aproveitar o potencial dos sistemas caóticos no sentido da emergência de novos conhecimentos. Inicialmente, leva-se o sistema até o limite do caos, desorganizando e fragmentando os materiais textuais da análise. A partir disso, possibilita-se a formação de novas estruturas de compreensão dos fenômenos sob investigação, expressas então em forma de produções escritas. (MORAES, 2003, p. 210)
\end{abstract}

Desse modo, o processo pode ser compreendido com base nas ideias dos sistemas complexos e auto-organizados e descrito como um ciclo de operações que seguem uma sequência recursiva (MORAES, 2003), o qual procuramos representar na Figura 1.

\title{
Fig. 1: Ciclo de operações da análise textual discursiva
}

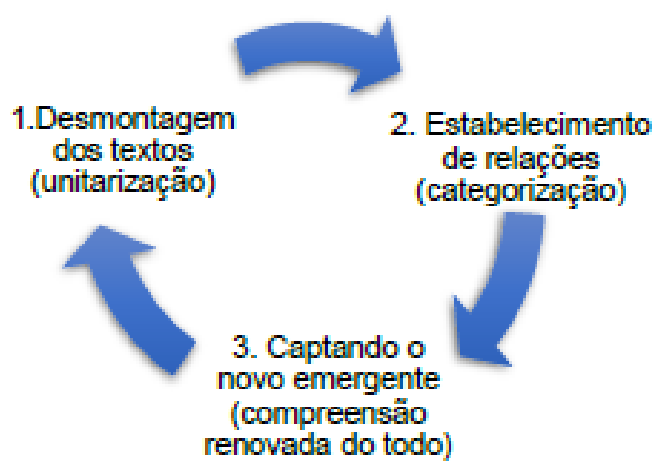

Fonte: dos autores.

O processo parte da unitarização dos materiais do corpus, isto é, da desconstrução dos materiais textuais selecionados. O conjunto de documentos que compõe o corpus deve ser selecionado e delimitado de forma rigorosa, definindo-se uma amostra a partir de um conjunto maior de textos, que podem ser produzidos especialmente para a pesquisa, como foi o caso das entrevistas semiestruturadas que realizamos, ou documentos existentes previamente, como os textos das políticas oficiais do ProEMI que analisamos. Por meio da desconstrução e 
unitarização do corpus, são definidas unidades de análise, denominadas também unidades de significado ou de sentido, que devem estar em consonância com os propósitos da pesquisa.

Em seguida, o processo move-se pela categorização das unidades de análise, que pode ser entendida como "um processo de comparação constante entre as unidades definidas no processo inicial da análise, levando a agrupamentos de elementos semelhantes. Os conjuntos de elementos de significação próximos constituem as categorias" (MORAES, 2003, p. 197) que podem ser definidas a priori ou emergirem dos dados do corpus.

Por último, segue para a argumentação e produção do metatexto, cujos elementos de organização são as categorias definidas anteriormente. A partir delas são produzidas as descrições e interpretações expressas em forma de argumentação. O metatexto é, portanto, composto por novas estruturas de compreensão dos fenômenos investigados, sob a forma de produção escrita, que dependem dos pressupostos teóricos e epistemológicos assumidos pelo pesquisador ao longo do trabalho (MORAES, 2003).

A análise textual discursiva tem no exercício da escrita seu fundamento enquanto ferramenta mediadora na produção de significados e por isso, em processos recursivos, a análise se desloca do empírico para a abstração teórica, que só pode ser alcançada se o pesquisador fizer um movimento intenso de interpretação e produção de argumentos. Este processo todo gera meta-textos analíticos que irão compor os textos interpretativos. (MORAES; GALIAZZI, 2006, p. 118)

Ainda, de acordo com Moraes e Galiazzi (2006) essa abordagem de análise de dados transita entre duas formas consagradas de análise na pesquisa qualitativa que são a análise de conteúdo (interpretação do significado atribuído pelo autor) e a análise de discurso (condições de produção de um determinado texto). As múltiplas significações e os diferentes sentidos que podem ser lidos em um texto são levados em conta, considerando os diferentes pressupostos teóricos que cada leitor utiliza em suas leituras em um dado contexto histórico-social. Para Moraes (2003, p. 194), os textos, entendidos como produções linguísticas, são considerados "produtos que expressam discursos sobre fenômenos e que podem ser lidos, descritos e interpretados, correspondendo a uma multiplicidade de sentidos que a partir deles podem ser construídos".

Sendo assim, os sentidos que o leitor/sujeito dá ao corpus evidenciam uma compreensão de linguagem que não é neutra, mas ideológica e carregada de pressupostos (MORAES, 2003). Para Bernstein e Díaz (1985), o discurso não pode ser reduzido a uma simples realização da linguagem ou às intenções livres de um sujeito que articula significados. $\mathrm{O}$ discurso consiste, então, em uma categoria abstrata, o produto de uma complexa rede de 
relações sociais. A ordem discursiva é intrínseca à ordem não discursiva, ou seja, à ordem social dominante na qual está situado e a qual reproduz. Assim, o discurso pode ser considerado uma categoria na qual sujeitos e objetos se constituem, de maneira articulada com as relações de poder e controle. O poder, portanto, está presente em cada discurso e, por sua vez, cada discurso pode ser considerado um mecanismo de poder.

Levando em consideração os pressupostos teórico-metodológicos apresentados e as tensões presentes na pesquisa em política educacional entre preocupações com eficiência e com justiça social (BALL, 2011), optamos por uma ética mais voltada para a segunda, na qual as pessoas são dotadas de voz. Para analisar os dados, partimos dos discursos presentes nos textos da política e nas falas dos profissionais da escola, com atenção para as expressões, os posicionamentos, as crenças e sua relação com a ordem social na qual se inserem. Isso porque acreditamos ser preciso evitar a simples culpabilização da escola ou de seus profissionais e buscar uma reflexão crítica localizada nos contextos global e local, assim como no tempo histórico específico.

\section{O DESENHO DA PESQUISA}

Para melhor compreensão das imbricações entre as opções teóricas e metodológicas, apresentamos o desenho da pesquisa realizada (Figura 2), com o cenário de investigação, os atores sociais, os objetivos e os procedimentos de geração e análise dos dados.

Quanto ao cenário trata-se de uma escola da Rede Estadual de SC, localizada no município de Rio do Sul, que atualmente atende aos anos finais do Ensino Fundamental e ao Ensino Médio. Em 2016, ano em que iniciamos a etapa de geração de dados desta pesquisa, a escola contava com 86 alunos matriculados no ProEMI.

\section{Fig. 2: Desenho da pesquisa}


OBJETIVO GERAL

Compreender como a política de redesenho curricular do ProEMI é recontextualizada do macro ao microcontexto.

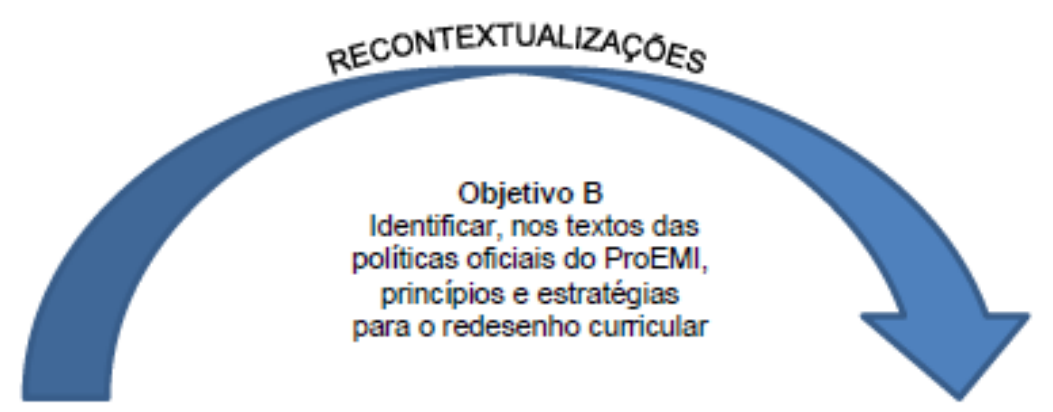

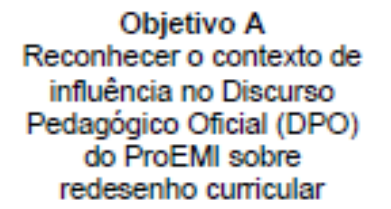

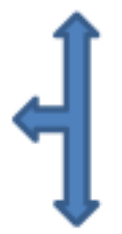

- Análise documental de textos das políticas oficiais do ProEMI (nacionais e estaduais) do período de 2009 a 2016
- Análise documental do Projeto de Atividades Integradoras da Escola; - Entrevistas semiestruturadas com os atores sociais

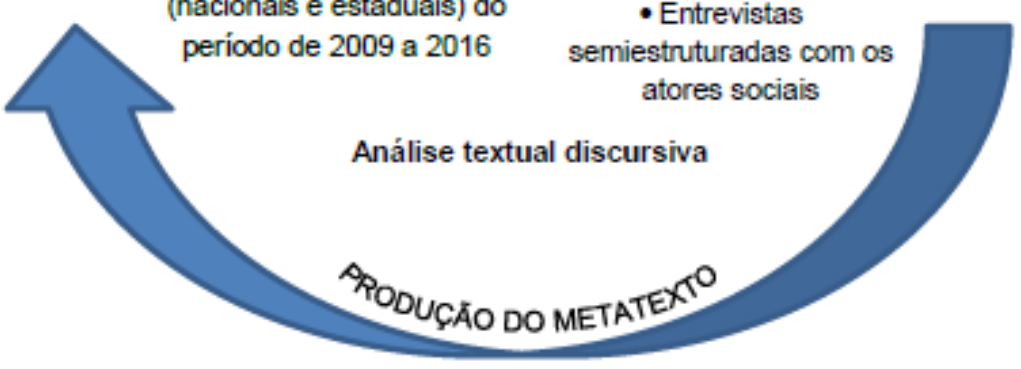
Analisar a "atuação da política" de redesenho curricular do ProEMI no contexto da prática

Fonte: dos autores.

Considerando a necessidade de definir uma amostra para a realização de uma análise mais consistente, optamos por fazer um recorte, focando especificamente na área de Linguagens ${ }^{6}$ : Língua Portuguesa e Literatura; Língua Estrangeira Inglês; Arte; Educação Física e Informática. É importante reforçar, ainda, que questões inerentes à Linguagem têm sido objeto de discussão e foco de propostas de ações e políticas educacionais no Brasil, em busca do enfrentamento de problemas relacionados à alfabetização e ao letramento.

Os atores sociais envolvidos foram os profissionais da equipe de gestão da escola que mantêm uma relação direta com o ProEMI e professores da área de Linguagens, que poderiam contribuir significativamente para a investigação. $O$ grupo selecionado ficou assim constituído: um professor de cada disciplina da área de Linguagens, as orientadoras de leitura

\footnotetext{
${ }^{6}$ Conforme Matriz Curricular do ProEMI em vigência na escola.
} 
e de convivência ${ }^{7}$, a diretora, uma assessora de direção e a Assistente Técnico-Pedagógica responsável pela articulação do Programa na escola, totalizando dez sujeitos da pesquisa.

Partindo da base teórica e analítica já apresentada, traçamos os objetivos específicos da pesquisa. De acordo com esses objetivos, foram definidos os procedimentos de geração e análise de dados, conforme Figura 1.

$\mathrm{O}$ primeiro objetivo específico desta pesquisa pretendia reconhecer o contexto de influência no Discurso Pedagógico Oficial (DPO) do ProEMI sobre redesenho curricular. Os dados foram gerados a partir da análise documental de textos das políticas oficiais do ProEMI (nacionais), do período de 2009 a 2016, nos quais buscamos por influências na elaboração do DPO e os grupos que as representam, considerando seus interesses (intenções e propósitos). Para este objetivo, analisamos o Parecer CNE/CP n. ${ }^{\circ}$ 11/2009 que trata da Proposta de experiência curricular inovadora do Ensino Médio (BRASIL, CNE/CP, 2009) e os Documentos Orientadores do ProEMI (BRASIL, MEC/SEB, 2009, 2011, 2013 e 2014).

A noção de "documento" adotada aqui parte da perspectiva de Cellard (2012, p. 297) que inclui nesse conceito "todo texto escrito, manuscrito ou impresso", considerando "as fontes, primárias ou secundárias, que, por definição, são exploradas - e não criadas - no contexto de um procedimento de pesquisa”. A análise documental, portanto, pode ser útil para esta fase da pesquisa pois, segundo o Cellard (2012) é primordial, em todas as etapas, o exame do contexto social global de produção do documento, incluindo os autores e aqueles a quem ele foi destinado, seja qual tenha sido a época em que o texto tenha sido escrito. Assim, é necessário conhecer a conjuntura política, econômica, social e cultural envolvida na produção do documento.

O segundo objetivo específico buscou identificar e problematizar, a partir dos textos das políticas oficiais do ProEMI, princípios e estratégias para o redesenho curricular. Isso porque atribuímos ao ProEMI, e consequentemente sua proposta de redesenho curricular, o mesmo sentido que Ball e Mainardes (2011) atribuem à política. Para os autores, ela pode estar relacionada à organização das práticas e à relação que essas práticas têm com alguns princípios. Desse modo, além dos documentos nacionais mencionados acima, analisamos, no âmbito estadual, o documento intitulado ORIENTAÇÕES: Organização e funcionamento das

\footnotetext{
7 Na Rede Estadual de SC, para atender ao ProEMI, as escolas contam com uma equipe de gestão da aprendizagem composta por professores que atuam como Orientadores, sendo um de Leitura, um de Convivência e outro de Laboratório nas áreas de Ciências da Natureza e Matemática. (SANTA CATARINA, SED/DIEB, 2016). Optamos por incluir os orientadores de Leitura e de Convivência entre os atores sociais entrevistados por ambos terem formação na Área de Linguagens (Letras e Educação Física), pelas ações que desenvolvem aproximam-se mais de sua área de formação e pela sua ampla relação com a comunidade escolar.
} 
unidades escolares de educação básica e profissional da rede pública estadual, para os anos letivos 2015/2016 (SANTA CATARINA, SED/DIEB, 2014) e a Matriz Curricular do ProEMI adotada no cenário da pesquisa.

Concebemos a escola também como produtora de texto, enquanto responsável pelo redesenho curricular e consideramos as recontextualizações da política que ocorrem nesse contexto. Por isso, o terceiro objetivo procurou analisar a "atuação da política" de redesenho curricular do ProEMI no contexto da prática. Com esse intuito, os dados foram gerados de duas formas: por meio de entrevistas semiestruturadas realizadas com os atores sociais da pesquisa, seguindo um roteiro com questões norteadoras adaptado de Mainardes (2006), e através de análise documental do Projeto de Atividades Integradoras da escola.

Visando à proteção da instituição pesquisada e dos atores sociais entrevistados, incluindo a preservação de suas identidades, tivemos uma preocupação especial com a ética na pesquisa, incluindo a elaboração e utilização do Termo de Consentimento Livre e Esclarecido. O projeto foi submetido e aprovado pelo Comitê de Ética, sob Parecer Consubstanciado.

O uso de entrevistas é sugerido por Mainardes (2006) tanto para a análise do contexto da produção de texto quanto do contexto da prática. Tal opção permitiu, assim como defende Duarte (2004), o cruzamento dos dados da entrevista semiestruturada com as referências teórico/conceituais para a construção de um novo texto, articulando a fala dos diferentes informantes através de um "diálogo artificial”, identificando recorrências, concordâncias, contradições, divergências, etc.

Segundo Duarte (2004), esse procedimento ajuda a compreender as relações presentes no contexto e o modo como os diferentes interlocutores percebem o problema. Para o autor, é preciso, ainda, "desconfiar" dos interlocutores pois, muitas vezes, os entrevistados "encenam um personagem" que corresponde ao que, intuitivamente, acreditam que o pesquisador deseja que ele seja, dizendo o que ele gostaria de ouvir. No entanto, a fala do entrevistado tem valor em si mesma, e não pode ser usada somente como ilustração das teorias. Esses depoimentos podem fornecer subsídios e base para o questionamento de pressupostos e concepções estabelecidas e consolidadas, ao refutar hipóteses que o pesquisador tinha antes de realizar a entrevista. Esse, portanto, precisa estar aberto às surpresas, ao novo, mesmo que seja necessário rever conceitos e refazer o caminho já trilhado. 
Os documentos oficiais do ProEMI, as transcrições das entrevistas - gravadas em dispositivos eletrônicos com autorização dos atores sociais - e o Projeto de Atividades Integradoras da escola formaram, portanto, o corpus para a ATD.

\section{COMUNICAÇÃO DAS COMPREENSÕES EMERGENTES DA ANÁLISE}

Desde as primeiras ideias para a escolha do objeto de pesquisa, o diálogo com a base teórica ajudou-nos a ter uma visão menos ingênua das políticas educacionais. Nesse sentido, as leituras sobre recontextualização, sobre o Ciclo de Políticas e, mais recentemente, sobre a Teoria da Atuação, contribuíram significativamente para traçarmos um caminho para seguir. Recorremos à ATD para que não nos perdêssemos na caminhada e pudéssemos superar o desafio de relacionar conceitos e dados de forma coerente, para descrevê-los, interpretá-los e, quando conseguimos ir tão longe, argumentar sobre eles. Nesse movimento, permeado de insights inesperados que traziam novas compreensões sobre o objeto investigado, frequentemente fomos do caos à ordem e vice-versa, conscientes da necessidade do rigor científico.

Reconhecemos a importância do contexto de influência, que desvela os porquês de uma política ter sido idealizada, elaborada e colocada em ação num determinado tempo histórico. Dentre os vários motivos para a produção do DPO do ProEMI sobre redesenho curricular, os resultados da pesquisa apontam para dados estatísticos sobre o EM, outras políticas em vigor e debates anteriores no âmbito do MEC. A análise ainda mostra que a produção da política é resultante da circulação de discursos, nacionais e internacionais, recontextualizados nos textos das políticas oficiais analisadas.

Nesses textos, identificamos alguns princípios para o redesenho curricular, nem sempre explícitos, mas coerentes com as estratégias de organização das práticas. Agrupamos esses princípios em quatro categorias: 1) formação humana integral com qualidade social; 2) trabalho como princípio educativo e direitos humanos como princípio norteador; 3 ) inovações curriculares e pedagógicas; 4) autonomia com autorresponsabilidade.

Esses princípios foram traduzidos pelos elaboradores da política no macrocontexto (MEC) em algumas estratégias de organização das práticas, que "tentam dizer" como colocar a política em prática. Agrupamos e sintetizamos essas estratégias em: 1) integração curricular; 2) reorganização do tempo/espaço pedagógico; 3) gestão democrática, com novos modos de regulação. 
As recontextualizações do DPO nacional pela Secretaria de Estado da Educação de SC, resultaram em orientações (documentos destinados às escolas) para a atuação do ProEMI no contexto da prática. Do nosso ponto de vista, tais orientações estreitaram as possibilidades de inovação previstas pelos documentos do MEC, mas ainda trazem aberturas significativas para inovações curriculares e pedagógicos no contexto da prática, se compararmos com a realidade do Ensino Médio regular.

Apesar de utilizar estratégias de gerenciamento provenientes da lógica do mercado, há uma preocupação na proposta em proporcionar mudanças significativas na qualidade do EM público, este visto sob uma perspectiva de formação humana integral e direito universal. No entanto, é nas escolas que as políticas acontecem, colocando em cena uma série de tensões que precisam ser administradas pelos atores sociais, relacionadas ao que Ball, Maguire e Braun (2016) denominam "dimensões contextuais da atuação da política": 1) contextos situados; 2) culturas profissionais; 3) contextos materiais; 4) contextos externos. Ao analisar a atuação do ProEMI, no que se refere a lidar com o redesenho curricular, entrevemos nas falas dos atores sociais que a maioria das tensões está mais relacionada às culturas profissionais. Todavia, também são marcantes as tensões existentes nas demais dimensões contextuais.

A análise da atuação do ProEMI no contexto da prática revelou, também, algumas recontextualizações do DPO (nacional e estadual) sobre redesenho curricular, que entendemos como inovações que emergem da atuação da política: 1) reorganização do currículo, com tempos e espaços mais favoráveis à formação humana integral com qualidade; 2) ressignificação da ação docente e dos espaços coletivos, ampliando as possibilidades de integração curricular; 3) empoderamento dos atores sociais, decorrente da gestão que promove a autonomia e a participação.

Nosso argumento principal, a partir compreensões trazidas pela pesquisa, é que o ProEMI consiste em uma política de redesenho curricular ampla, complexa e realmente inovadora, voltada para a qualidade social no EM. No entanto, a flexibilidade da proposta pode levar a recontextualizações locais que limitem seu alcance. Por consequência, torna-se apenas uma medida paliativa, que não resolve os problemas a que se propõe, visto que não consegue alcançar a maioria dos estudantes do EM, reforçando os tradicionais processos de exclusão

Apesar das inovações, em alguns casos ainda modestas, o DPO parece "bom demais para ser verdade", havendo um distanciamento entre o que dizem os textos da política e o que ocorre na prática. Não se pode negar, porém, as consequências positivas para as escolas que 
redesenharam seus currículos a partir do ProEMI. Faz-se necessário olhar para as tensões que emergem da atuação da política e para as ações e experiências inovadoras que trouxeram resultados positivos como exemplos para redesenhar os currículos a partir da nova reforma do EM que já está em curso.

Ao fim do percurso da pesquisa, podemos afirmar que o processo pode ter sido uma experiência tão ou mais enriquecedora que o produto final. Apesar da complexidade da tarefa a que nos propomos, aceitamos o desafio, não sem uma boa dose de insegurança, mas na certeza da necessidade de seguir adiante.

Nesse sentido, a ATD revelou-se uma abordagem de análise de dados adequada e coerente com a proposta de investigação. As opções teóricas e metodológicas imbricadas e somadas a conceitos que buscamos em outras referências, conforme as demandas trazidas pelas categorias emergentes, revelaram significados e sentidos emergentes do corpus, necessários para as descrições, as interpretações e as argumentações que resultaram no texto final.

Concluímos, a partir da trajetória da pesquisa, que o quadro teórico-metodológico contribuiu significativamente para analisarmos a política de forma mais ampla, considerando as recontextualizações que ocorrem do macro ao microcontexto, e com um olhar respeitoso para aqueles que fazem a política acontecer na escola.

\section{REFERÊNCIAS}

ANDRADE, Marcia Regina Selpa de. Recontextualização do currículo integrado nos cursos de medicina da UFSC e UNOCHAPECÓ. 2012. Tese (Doutorado em Educação) Universidade Estadual de Campinas, Faculdade de Educação, Campinas, 2012.

BALL, Stephen J. Educação Global SA: novas redes políticas e o imaginário neoliberal. Tradução de Janete Bridon. Ponta Grossa: UEPG, 2014.

BALL, Stephen J. Educational reform: a critical and post-structural approach. Buckingham: Open University Press, 1994.

BALL, Stephen J.; MAGUIRE, Meg; BRAUN, Annette. Como as escolas fazem as políticas: atuação em escolas secundárias. Tradução de Janete Bridon. Ponta Grossa: UEPG, 2016.

BALL, Stephen; MAINARDES, Jefferson (Orgs.). Políticas educacionais: questões e dilemas. São Paulo: Cortez, 2011.

BALL, Stephen J. Sociologia das políticas educacionais e pesquisa crítico-social: uma revisão pessoal das políticas educacionais e da pesquisa em política educacional. In: BALL, Stephen 
J.; MAINARDES, Jefferson (Orgs.). Políticas educacionais: questões e dilemas. São Paulo: Cortez, 2011, p. 21-53.

BERNSTEIN, Basil. A Estruturação do discurso pedagógico: classe, códigos e controle. Petrópolis: Vozes, 1996

BERNSTEIN, Basil. Pedagogía, control simbólico e identidad. Madrid: Morata, 1998.

BERNSTEIN, Basil; DÍAZ, Mario. Hacia una teoría del discurso pedagógico. Revista Colombiana de Educación, n. 15, p. 105-153, set. 1985.

BOWE, Richard.; BALL, Stephen J; GOLD, Anne. Reforming education \& changing schools: case studies in Policy Sociology. London: Routledge, 1992.

BRASIL. CNE/CP. Proposta de experiência curricular inovadora do Ensino Médio. Parecer n. 11, de 30 de junho de 2009. Relator: Francisco Aparecido Cordão. Diário Oficial da União, Brasília: 25 ago. 2009.

BRASIL. MEC/SEB. Programa Ensino Médio Inovador - Documento Orientador. Brasília: 2009.

BRASIL. MEC/SEB. Programa Ensino Médio Inovador - Documento Orientador. Brasília: 2011.

BRASIL. MEC/SEB. Programa Ensino Médio Inovador - Documento Orientador. Brasília: 2013.

BRASIL. MEC/SEB. Programa Ensino Médio Inovador - Documento Orientador. Brasília: 2014.

CELLARD, André. A análise documental. In: POUPART, Jean, et al. A pesquisa qualitativa: enfoques epistemológicos e metodológicos. Tradução de Ana Cristina Nasser. 3. Ed. Petrópolis: Vozes, 2012. p. 295-316.

DUARTE, Rosália. Entrevistas em pesquisas qualitativas. Educar em revista, Curitiba, v. 24, p. 213-225, 2004.

LOPES, Alice Casimiro. Política de Currículo: Recontextualização e Hibridismo. Currículo sem fronteiras, v. 5, n. 2, p. 50-64, 2005.

MAINARDES, Jefferson. Abordagem do ciclo de políticas: uma contribuição para a análise de políticas educacionais. Educação e Sociedade, Campinas, v. 27, n. 94, p. 47-69, jan./abr.2006.

MAINARDES, Jefferson.; MARCONDES, Maria Inês. Entrevista com Stephen J. Ball: um diálogo sobre justiça social, pesquisa e política educacional. Educação \& Sociedade, Campinas, v. 30, n. 106, p. 303-318, jan./abr. 2009.

MAINARDES, Jefferson; FERREIRA, Márcia dos Santos; TELlO, César. Análise de políticas: fundamentos e principais debates teórico-metodológicos. In: BALL, Stephen J.; 
MAINARDES, Jefferson (Orgs.). Políticas educacionais: questões e dilemas. São Paulo: Cortez, 2011. p. 143-172.

MAINARDES, Jefferson; STREMEL, Silvana. A teoria de Basil Bernstein e algumas de suas contribuições para as pesquisas sobre políticas educacionais e curriculares. Revista Teias, Rio de Janeiro, v. 11, n. 22, p. 31-54, maio/ago. 2010.

MORAES, Roque. Uma tempestade de luz: a compreensão possibilitada pela análise textual discursiva. Ciência \& Educação, v. 9, n. 2, p. 191-211, 2003.

MORAES, Roque; GALIAZZI, Maria do C. Análise textual discursiva: Processo reconstrutivo de múltiplas faces. Ciência \& Educação, v. 12, n. 1, p. 117-128, 2006.

PEREIRA, Ricardo Inocêncio. Redesenho curricular no Programa Ensino Médio Inovador: recontextualizações da política. 2017. Dissertação (Mestrado em Educação) - Universidade Regional de Blumenau, Blumenau, 2017.

SANTA CATARINA. SED/DIEB. Documento para professores orientadores do ProEMI. Florianópolis, 2016.

SANTA CATARINA. SED/DIEB. ORIENTAÇÕES: Organização e funcionamento das unidades escolares de educação básica e profissional da rede pública estadual, para os anos letivos 2015/2016. Florianópolis: nov. 2014. p.21-27.

Data de recebimento: $18 / 07 / 2017$

Data de aceite: $30 / 10 / 2017$ 